\title{
Efficient Near-Infrared-Transparent Perovskite Solar Cells Enabling Direct Comparison of 4-Terminal and Monolithic Perovskite/Silicon Tandem Cells
}

Jérémie Werner, ${ }^{* \dagger}{ }^{\dagger}$ Loris Barraud, ${ }^{\ddagger}$ Arnaud Walter, ${ }^{\ddagger}$ Matthias Bräuninger, ${ }^{\dagger}$ Florent Sahli, $^{\dagger}$ Davide Sacchetto, ${ }^{\ddagger}$ Nicolas Tétreault, ${ }^{\ddagger}$ Bertrand Paviet-Salomon, ${ }^{\ddagger}$ Soo-Jin Moon, ${ }^{\ddagger}$ Christophe Allebé, Matthieu Despeisse, ${ }^{\ddagger}$ Sylvain Nicolay, ${ }^{\ddagger}$ Stefaan De Wolf, ${ }^{\dagger}$ Bjoern Niesen, ${ }^{*},+\ddagger$ and Christophe Ballif ${ }^{\dagger, \ddagger}$

${ }^{\dagger}$ Ecole Polytechnique Fédérale de Lausanne (EPFL), Institute of Microengineering (IMT), Photovoltaics and Thin-Film Electronics Laboratory, Rue de la Maladière 71b, 2002 Neuchâtel, Switzerland

${ }^{\ddagger}$ CSEM, PV-Center, Jaquet-Droz 1, 2002 Neuchâtel, Switzerland

\section{Supporting Information}

ABSTRACT: Combining market-proven silicon solar cell technology with an efficient wide band gap top cell into a tandem device is an attractive approach to reduce the cost of photovoltaic systems. For this, perovskite solar cells are promising high-efficiency top cell candidates, but their typical device size $\left(<0.2 \mathrm{~cm}^{2}\right)$, is still far from standard industrial sizes. We present a $1 \mathrm{~cm}^{2}$ near-infrared transparent perovskite solar cell with $14.5 \%$ steadystate efficiency, as compared to $16.4 \%$ on $0.25 \mathrm{~cm}^{2}$. By mechanically stacking these cells with silicon heterojunction cells, we experimentally demonstrate a 4-terminal tandem measurement with a steady-state efficiency of $25.2 \%$, with a $0.25 \mathrm{~cm}^{2}$ top cell. The developed top cell processing methods enable the fabrication of a $20.5 \%$ efficient and $1.43 \mathrm{~cm}^{2}$ large monolithic perovskite/silicon heterojunction tandem solar cell, featuring a rear-side textured bottom cell to increase its near-infrared spectral response. Finally, we compare both tandem configurations to identify efficiency-limiting factors and discuss the potential for further performance improvement.

1 he photovoltaic market has been dominated by waferbased silicon technologies for several decades, thanks to their excellent reliability, high efficiencies, and continued rapid reduction in manufacturing costs at the cell and module level. As a result of low module costs, the balanceof-system costs are now becoming the main contributors to the overall photovoltaic system price, which must be further reduced to keep improving the competitiveness of photovoltaics with other energy sources. ${ }^{1,2}$ Because most balance-ofsystem costs scale with module area, they can effectively be reduced by increasing module efficiency. However, with record efficiencies of up to $25.6 \%$, wafer-based silicon solar cells are already very close to their commonly accepted practical limit of $\sim 26 \%{ }^{3-5}$ such that new concepts have to be found to significantly further improve performance. One of the most promising approaches lies in reducing thermalization losses by utilizing a multijunction configuration in which the silicon cell is combined with a wide band gap cell. In a tandem device, the wide band gap top cell harvests high-energy photons and overlies a silicon bottom cell that absorbs low-energy photons.
This is why the amorphous silicon/crystalline silicon heterojunction ( $\mathrm{SHJ}$ ) solar cell is a promising bottom cell technology; it provides not only high overall performance but also excellent spectral responsivity in the near-infrared spectral region. ${ }^{6}$ Considering overall tandem performance, solar cells based on III-V materials have been shown to be ideal candidates for the top cell, with their high efficiencies and appropriate wide band gap. Recently, mechanically stacked InGaP/Si tandem cells were demonstrated with a total efficiency of up to $29.8 \%{ }^{7}$ However, III-V materials still rely on costly deposition methods, which limits their usage to niche applications, such as space or concentrator photovoltaics. ${ }^{8}$

Organic-inorganic halide perovskite solar cells have recently emerged as a low-cost alternative for top cells. In addition to enabling high initial single-junction efficiencies of up to

Received: July 8, 2016

Accepted: July 30, 2016

Published: July 30, 2016 
a)

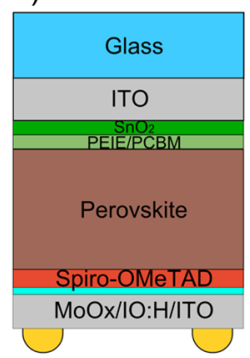

b)

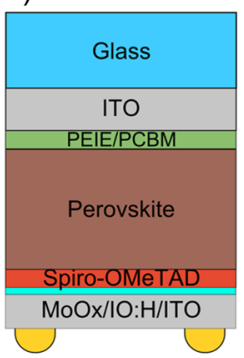

C) $100^{\circ} \mathrm{C}$ annealing

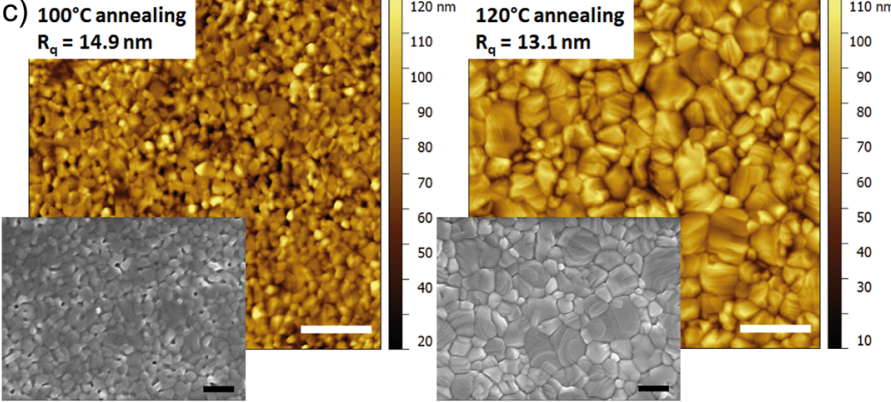

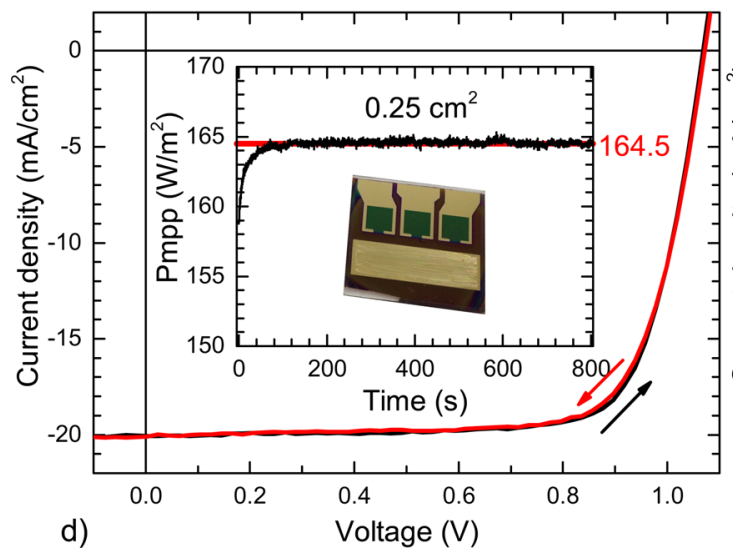

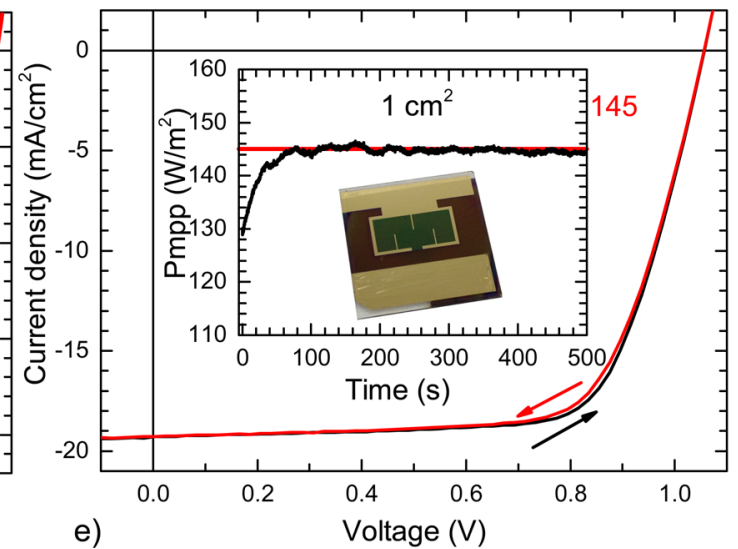

Figure 1. NIR-transparent perovskite cells. Panels a and b show the layouts of planar perovskite cells with and without SnO in the electron transport layer stack. Panel c presents AFM height maps and SEM images of perovskite layers grown with an ethanol-based methylammonium iodide solution, annealed at 100 and $120{ }^{\circ} \mathrm{C}$. SEM scale bars equal $500 \mathrm{~nm}$, and AFM scale bars equal $1 \mu \mathrm{m}$. Panels d and e show $J-V$ characteristics of NIR-transparent planar perovskite cells with aperture area of $0.25 \mathrm{~cm}^{2}\left(\right.$ without $\left.\mathrm{SnO}_{2}\right)$ and $1.015 \mathrm{~cm}^{2}\left(\right.$ with $\mathrm{SnO}_{2}$ ), respectively. The insets show photographs as well as maximum power point tracking curves of these cells.

$22.1 \%,{ }^{9,10}$ organic-inorganic halide perovskite materials have been shown to have excellent properties for tandem applications, namely a steep absorption edge ${ }^{11}$ and a band gap readily adjustable to the ideal value of $1.7-1.8 \mathrm{eV} \cdot{ }^{12-14}$ As a result, perovskite/silicon tandem cells are expected to have the potential for high efficiencies beyond $30 \% .^{15-17}$

Multijunction solar cells can be made mainly with three different configurations: spectral splitting and mechanically stacked or monolithically integrated tandems. With spectral splitting, efficiencies up to $28 \%$ were demonstrated using an opaque perovskite cell, a SHJ cell, and an optical system designed to split the solar spectrum adequately on the two subcells, which are processed and measured independently. ${ }^{18,19}$ However, this technique is sensitive to the light angular distribution and cannot be considered suitable for flat-plate photovoltaic collectors. Flat-plate multijunctions can be realized with 2- or 4-terminal tandem devices. The 4-terminal tandem can be fabricated by mechanically stacking a near-infrared (NIR)-transparent perovskite top cell onto a bottom cell. This configuration does not require a complex optical system while still offering a large degree of freedom concerning subcell processing as well as device polarity. Also, a high performance can be reached with a broad range of top cell band gaps. $^{15,16,20-23}$ Several groups have been working on this configuration, combining perovskite top cells with either silicon or chalcogenide bottom cells, ${ }^{14,24-27}$ with reported efficiencies of up to $23 \%$ on silicon. ${ }^{28}$ In parallel, the development of monolithic tandem cells, where the top cell is directly grown onto the bottom cell, has also seen a fast evolution, with efficiencies increasing from $13.7 \%^{29}$ to $21.2 \%^{30,31}$ in just about a year. This configuration requires current matching and strict process compatibility between the two subcell technologies, making their manufacturing more challenging. Monolithic tandems can, however, be more easily integrated in a photovoltaic system, because of their 2-terminal design, which requires only one junction box where a 4-terminal tandem would need two. In addition, the monolithic design requires fewer transparent electrodes in the device, leading to reduced parasitic absorption.

However, despite these various reports on perovskite/silicon tandem cells, a significant performance gain compared to stateof-the-art single-junction silicon devices is yet to be demonstrated. Moreover, the reported semitransparent perovskite cells and perovskite-based mechanically stacked tandems were mainly demonstrated on small cell areas, typically $<0.2$ $\mathrm{cm}^{2}, 14,24-27,30,31$ despite the fact that the highest efficiency reported for an opaque perovskite cell with $1 \mathrm{~cm}^{2}$ aperture area was recently raised to $20.5 \% .^{32}$ Demonstrating tandem device performance on $>1 \mathrm{~cm}^{2}$ cell area is a necessary first step toward a potential future industrialization.

In this work, we demonstrate low-temperature planar NIRtransparent perovskite solar cells with $>1 \mathrm{~cm}^{2}$ aperture area and initial efficiencies of up to $14.5 \%$, and up to $16.4 \%$ with a cell area of $0.25 \mathrm{~cm}^{2}$. These efficient top cells allow us to demonstrate a significant performance gain in a mechanically stacked 4-terminal perovskite/SHJ tandem measurement, with total efficiencies of up to $23 \%$ and $25.2 \%$, for $1.015 \mathrm{~cm}^{2}$ and $0.25 \mathrm{~cm}^{2}$ top cell aperture area, respectively. The same top cell fabrication process was then used to fabricate perovskite/SHJ monolithic tandems with $20.5 \%$ efficiency for $>1 \mathrm{~cm}^{2}$ aperture area, as compared to $19.2 \%$ previously reported. ${ }^{31}$ This performance enhancement was made possible by introducing 
Table 1. Performance Overview for Single-Junction Silicon Heterojunction (SHJ) and NIR-Transparent Perovskite (PSC) Solar Cells, as well as 4-Terminal Mechanically Stacked Tandem Measurements and the Perovskite/SHJ Monolithic Tandem with Rear-Side Textured Bottom Cell ${ }^{a}$

\begin{tabular}{|c|c|c|c|c|c|c|c|}
\hline cell type & cell area $\left(\mathrm{cm}^{2}\right)$ & scan direction & $V_{\mathrm{oc}}(\mathrm{mV})$ & $J_{\mathrm{sc}}\left(\mathrm{mA} / \mathrm{cm}^{2}\right)$ & $\mathrm{FF}(\%)$ & eff. (\%) & $P_{\mathrm{mpp}}\left(\mathrm{mW} / \mathrm{cm}^{2}\right)$ \\
\hline \multirow[t]{2}{*}{ monolithic tandem } & 1.43 & forward & 1717 & 16.4 & 73.1 & 20.6 & 20.5 \\
\hline & 1.43 & reverse & 1718 & 16.4 & 70.0 & 19.7 & \\
\hline \multirow[t]{4}{*}{ PSC } & 1.015 & forward & 1057 & 19.3 & 71.6 & 14.6 & 14.5 \\
\hline & 1.015 & reverse & 1057 & 19.3 & 70.3 & 14.3 & \\
\hline & 0.25 & forward & 1069 & 20.1 & 76.1 & 16.3 & 16.4 \\
\hline & 0.25 & reverse & 1072 & 20.1 & 74.9 & 16.1 & \\
\hline SHJ, unfiltered & 4 & - & 718 & 38.7 & 79.4 & 22.05 & \\
\hline SHJ, filtered with $1 \mathrm{~cm}^{2}$ PSC & 4 & - & 692 & 15.5 & 79.4 & 8.5 & \\
\hline SHJ, filtered with $0.25 \mathrm{~cm}^{2}$ PSC & 4 & & 693 & 15.98 & 79.5 & 8.8 & \\
\hline \multicolumn{7}{|c|}{ 4-terminal tandem measurement with $\mathrm{SHJ}$ and PSC, $1 \mathrm{~cm}^{2}$} & 23.0 \\
\hline \multicolumn{7}{|c|}{ 4-terminal tandem measurement with $\mathrm{SHJ}$ and PSC, $0.25 \mathrm{~cm}^{2}$} & 25.2 \\
\hline
\end{tabular}

a“Reverse" stands for a $J-V$ scan from $V_{\text {oc }}$ to $J_{\text {sc }}$ and "forward" for a scan from $J_{\mathrm{sc}}$ to $V_{\mathrm{oc}} P_{\mathrm{mpp}}$ is the steady-state power extracted from maximum power point tracking measurements. Antireflective foils ${ }^{36,37}$ were used for all measurements. A black background was placed on the rear side of perovskite single-junction cells during $J-V$ measurements.

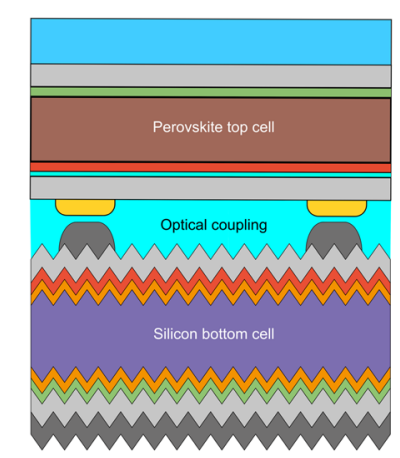

a)

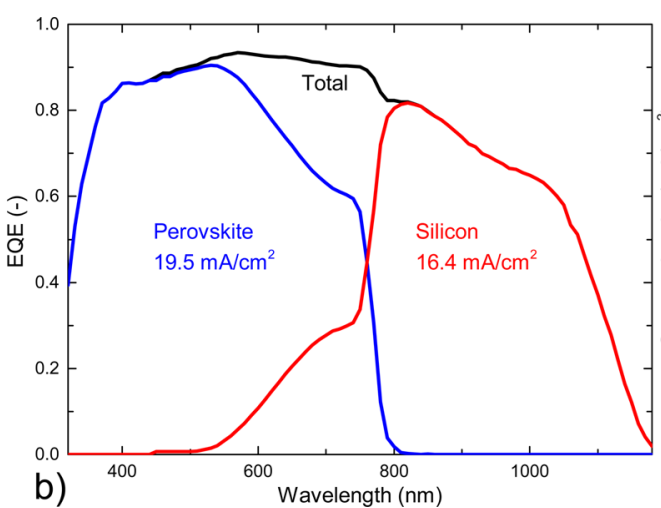

b)

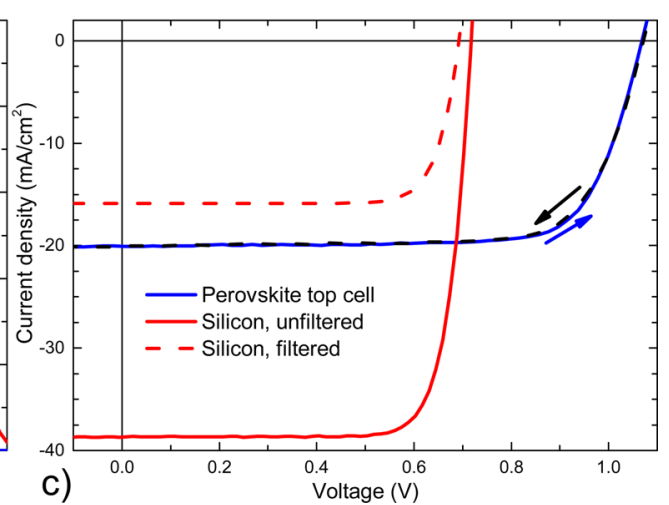

c)

Figure 2. 4-terminal mechanically stacked tandem: (a) schematic drawing of the tandem stack with a NIR-transparent perovskite top cell illuminated through the glass substrate (superstrate configuration) and a silicon heterojunction bottom cell; (b) EQE spectra and (c) $J-V$ characteristics of the mechanically stacked perovskite/SHJ tandem measurement with a $0.25 \mathrm{~cm}^{2}$ top cell and $25.2 \%$ total efficiency. Corresponding graphs for the $23 \%$ tandem with $1 \mathrm{~cm}^{2}$ top cell can be found in Figure S2 in the Supporting Information.

rear-side texture on the $\mathrm{SHJ}$ bottom cell, increasing its nearinfrared response. On the basis of these results, we compare both tandem configurations and discuss their potential for further performance improvement.

During the processing of a perovskite/SHJ monolithic tandem, the top cell is deposited directly onto the bottom cell. Because of the degradation of SHJ cell performance above $200{ }^{\circ} \mathrm{C}$, low perovskite deposition processes are strictly required. ${ }^{2}$ In our previous work, ${ }^{31}$ we presented a hybrid two-step deposition method which allowed us to fabricate pinhole-free perovskite layers with low surface roughness, with a device layout as shown in Figure $1 \mathrm{~b} . \mathrm{A} \mathrm{PbI}_{2}$ layer was first deposited by thermal evaporation and then transformed to the perovskite material by spin coating a solution of methylammonium iodide dissolved in a mixture of isopropanol and 2methoxyethanol. However, the use of solvents with stronger polarity, such as ethanol, was shown to be an effective method to yield smooth perovskite surfaces. ${ }^{33}$ In the present study, we therefore replaced the isopropanol-based solution by ethanol and increased the annealing temperature from 100 to $120^{\circ} \mathrm{C}$, which helped us to make uniform large-area perovskite layers with increased grain size of up to $500 \mathrm{~nm}$, as shown by the scanning electron microscopy (SEM) and atomic force microscopy (AFM) images in Figure 1c. From these AFM images, a surface roughness of $R_{\mathrm{rms}}=13.1 \mathrm{~nm}$ was obtained.
The electron transport layer was also optimized for larger cell areas, by introducing a $20 \mathrm{~nm}$ thick sputtered $\mathrm{SnO}_{2}$ layer between the front ITO and PEIE/PCBM layers, to enhance the uniformity of the electron transport layer stack and reduce possible shunt paths.

These improvements in film quality and uniformity allowed us to further improve the initial efficiency of our lowtemperature planar NIR-transparent perovskite solar cells to $16.4 \%$ and $14.5 \%$ for aperture areas of $0.25 \mathrm{~cm}^{2}$ and $1.015 \mathrm{~cm}^{2}$, respectively. These initial steady-state efficiencies were measured during maximum power point tracking for $>8 \mathrm{~min}$, as shown in the insets to Figure $1 \mathrm{~d}, \mathrm{e}$. Details on currentvoltage $(J-V)$ characteristics are given in Table 1 , including forward $\left(J_{\mathrm{sc}}\right.$ to $\left.V_{\mathrm{oc}}\right)$ and reverse $\left(V_{\mathrm{oc}}\right.$ to $\left.J_{\mathrm{sc}}\right)$ scans. The efficiency reduction when increasing the cell size is mainly attributed to a lower fill factor (FF), which decreased from $\sim 76 \%$ to $\sim 71 \%$. These FF losses can be explained by a higher series resistance in the larger cell of $9 \Omega \mathrm{cm}^{2}$, as compared to $5.3 \Omega \mathrm{cm}^{2}$ for the smaller one, obtained from fitting the $J-V$ curves. Additional efforts in metallization design and TCO deposition processes will be needed to further improve FF and overall cell performance of the $1 \mathrm{~cm}^{2}$ cell.

These NIR-transparent perovskite cells can directly be used in 4-terminal tandems, where they act as the top cell, mechanically stacked onto a SHJ bottom cell. Here, the 


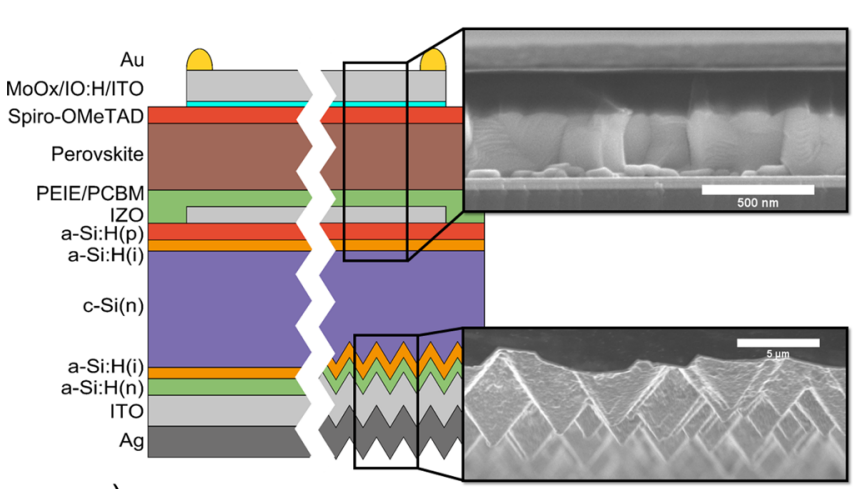

a)
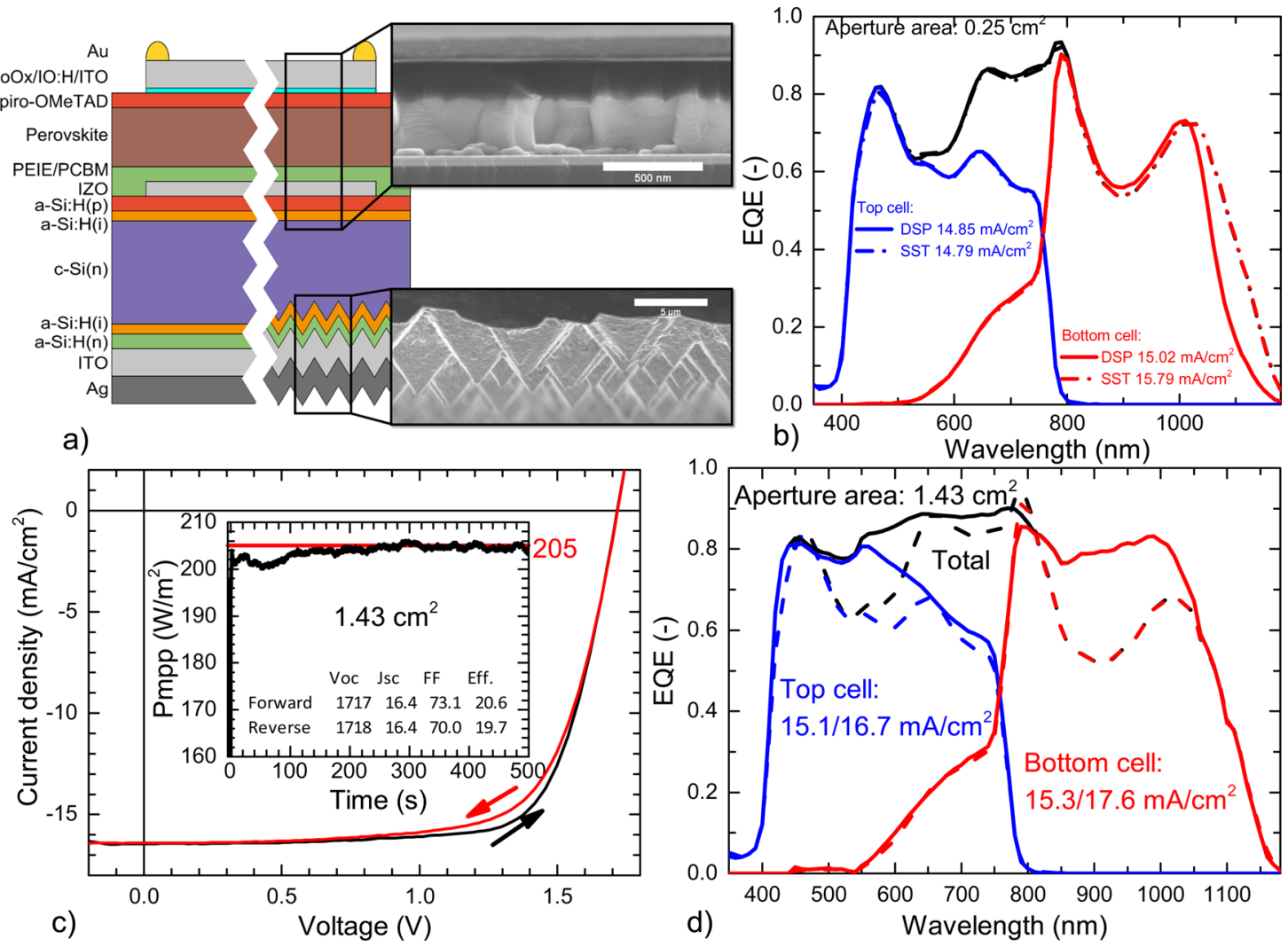

Figure 3. Monolithic tandem solar cell: (a) schematic drawings of monolithic tandem devices without and with rear-side texture and the corresponding SEM cross-section images for the front and rear side; (b) EQE spectra of monolithic tandem cells on double-side-polished (DSP) or single-side-textured (SST) bottom cells, without antireflective foil; (c) $J-V$ characteristics of a $1.43 \mathrm{~cm}^{2}$ monolithic tandem with SST silicon bottom cell, where the inset shows a steady power output under maximum power point tracking; (d) EQE spectra of the same tandem cell, measured with (solid lines) and without (dashed lines) antireflective foil.

development of a low-temperature-processed perovskite cell allows us to use ITO substrates, instead of the commonly used low-mobility $\mathrm{FTO},{ }^{10,14}$ which is an absolute requirement to minimize parasitic absorption in the near-infrared spectral region because of free-carrier absorption. ${ }^{27} \mathrm{~A}$ schematic of this tandem configuration is given in Figure 2a. The top cell was measured in superstrate configuration, illuminated through the glass substrate. An optical coupling liquid was used to optically connect the two subcells and reduce reflection losses. Because the two subcells used for these measurements had a significantly different active area $\left(4 \mathrm{~cm}^{2}\right.$ for the silicon cell and $0.25 \mathrm{~cm}^{2}$ or $1.015 \mathrm{~cm}^{2}$ for the perovskite cell), the tandem measurement was carried out with a previously reported method: ${ }^{27}$ First, the perovskite cell $J-V$ characteristics and external quantum efficiency (EQE) were measured independently from the silicon cell, using a black background to avoid reflection and current overestimation. Then, the EQE of the silicon cell was measured, while using the perovskite cell as an optical filter. Because of the silicon cell front-side metallization, a shadow losses factor (as defined in the Supporting Information) was used to correct the calculated current from the EQE curve of the filtered silicon cell. The resulting shortcircuit current density $\left(J_{\text {sc }}\right)$ corresponds to the current that the silicon cell would produce in the 4-terminal tandem configuration. Finally, the open-circuit voltage $\left(V_{\mathrm{oc}}\right)$ and FF of the silicon cell were obtained by adjusting the solar simulator's light intensity with neutral density filters to match the EQE-measured $J_{s c}$. The 4-terminal tandem measurement total efficiency is then equal to the sum of the NIR-transparent perovskite top cell and filtered $\mathrm{SHJ}$ bottom cell efficiencies.

Applying this characterization method and using the NIRtransparent perovskite cells presented above and a SHJ cell with an efficiency of $22 \%$, a 4-terminal mechanically stacked tandem was measured with a performance of up to $25.2 \%$ with the 0.25 $\mathrm{cm}^{2}$ perovskite cell and up to $23 \%$ with the $1.015 \mathrm{~cm}^{2}$ perovskite cell. More details on these results are presented in Figure 2 and Table 1. These tandem measurements show an efficiency improvement of $1-3 \%_{a b s}$, as compared to the singlejunction silicon cell, depending on the top cell size. This is a $2.2 \%$ abs performance increase compared to the previous 4 terminal perovskite/silicon tandem measurement record of $23 \%$ which had a $0.075 \mathrm{~cm}^{2}$ top cell. ${ }^{28}$ The experimental demonstration of efficiencies beyond $25 \%$ with this tandem configuration also confirms the potential of perovskite solar cells to boost the performance of high-efficiency silicon technology in tandem devices.

As mentioned above, monolithically integrated tandems are technically more challenging to realize because of strict process compatibility restrictions, also involving the requirement for a bottom cell with a sufficiently flat front surface for solutionprocessed top cells. Our previously reported monolithic perovskite/SHJ tandem cell thus featured a double-sidepolished (DSP) bottom cell and reached efficiencies of up to $19.2 \%$ for a cell area of $1.2 \mathrm{~cm}^{2}$. ${ }^{31}$ A major limitation of this device was the low spectral response at the silicon band edge due to the polished $\mathrm{SHJ}$ rear side. We therefore introduce here a single-side-textured (SST) SHJ bottom cell to enhance 
bottom cell current. Figure 3a provides schematic drawings of monolithic tandems with DSP and SST bottom cells, the only difference being the textured rear side. Details on the one-side texturing process are given in the Supporting Information. The improvement in spectral response is illustrated by Figure $3 b$, showing a comparison EQE spectra for monolithic tandems with DSP and SST bottom cells. We can observe that the rearside texture affects the EQE spectra only at wavelength $>1000$ $\mathrm{nm}$, as expected from the literature, ${ }^{23,34}$ enhancing the bottom cell current density by $0.77 \mathrm{~mA} / \mathrm{cm}^{2}$. This design upgrade of our monolithic tandem enabled us to fabricate a cell with up to $20.5 \%$ initial steady-state efficiency. The cell was measured with an aperture area of $1.43 \mathrm{~cm}^{2}$, and a microtextured antireflective foil was used to attenuate the interference pattern, increasing $J_{\mathrm{sc}}$ to $16.4 \mathrm{~mA} / \mathrm{cm}^{2}$. The device was consequently current-limited by the perovskite top cell, as shown by the tandem EQE curves in Figure 3d. To further improve tandem performance, the perovskite top cell will therefore need to generate a larger current.

Light management is in any near-future research scenario unarguably an essential topic in perovskite/silicon tandem development. Because we used the same top cell for both tandem configurations presented here, we can directly compare the mechanically stacked and monolithic tandem cells in terms of their parasitic absorption and light management requirements. The higher efficiency demonstrated here with the mechanically stacked configuration is directly linked to better light trapping, no necessity for current matching, and a free choice in top cell illumination direction. In this context, in a monolithic tandem, the currently used perovskite top cell has to be illuminated through the spiro-OMeTAD layer, leading to severe parasitic absorption in the UV and visible spectrum. ${ }^{31}$ These losses become apparent from Figure 4, by comparing the

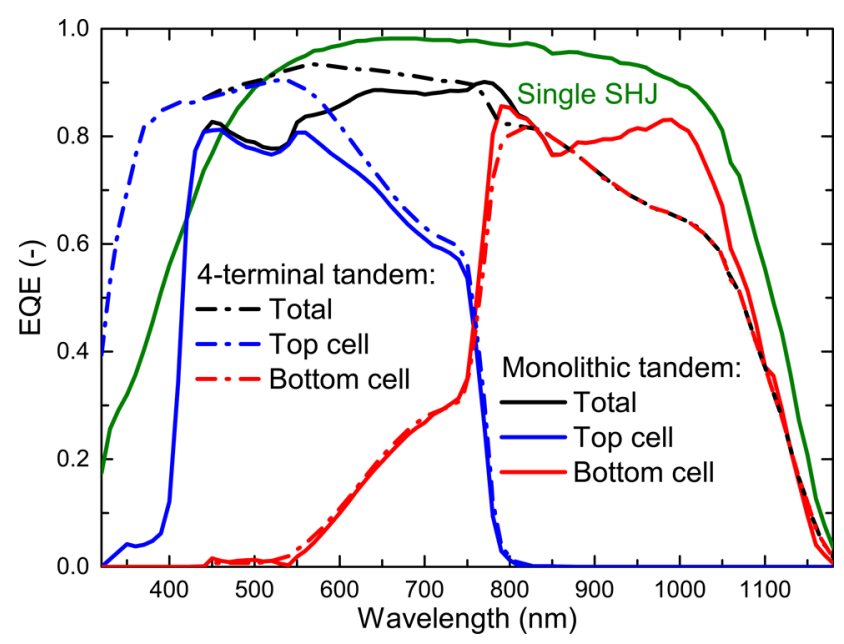

Figure 4. Comparison of EQE spectra from the $25.2 \%$ mechanically stacked tandem, the $20.5 \%$ monolithic tandem with SST bottom cell, and the $22 \%$ single-junction SHJ cell, which was also used as bottom cell in the mechanically stacked tandem. These EQE measurements were conducted using an antireflective foil.

spectral response in the $<400 \mathrm{~nm}$ wavelength range of both tandem configurations. The mechanically stacked tandem shows excellent performance in this spectral region, even outperforming the SHJ single-junction cell, which itself suffers from parasitic absorption in the amorphous silicon layers.
Overall, the perovskite top cell in the mechanically stacked configuration shows a $J_{\mathrm{sc}} 2.8 \mathrm{~mA} / \mathrm{cm}^{2}$ higher than that of the top cell in the monolithic tandem. By recovering about a third of these losses in the perovskite cell, the monolithic tandem would become current-limited by the bottom cell, even for the relatively thin perovskite cell used here. This clearly shows the necessity of moving to a larger top cell band gap for optimal monolithic tandem performance, which could be obtained by changing the currently used composition for a mixed-cation/ halide perovskite material, as recently discussed by several groups. ${ }^{10,14}$

The 4-terminal design of the mechanically stacked tandem, however, has a disadvantage: the presence of the additional transparent ITO contact in this configuration leads to a significant increase in parasitic absorption losses in the 850$1200 \mathrm{~nm}$ wavelength range due to free-carrier absorption. ${ }^{35}$ As a result, the bottom cell current in the monolithic tandem, which requires only a very thin IZO intermediate recombination layer, is $1.2 \mathrm{~mA} / \mathrm{cm}^{2}$ higher. Further current gains in the bottom cell of monolithic tandems are expected by replacing IZO with a thin-film silicon recombination layer.

Interestingly, in the 550-800 $\mathrm{nm}$ spectral region, where freecarrier absorption in the transparent contacts is still negligibly small, the bottom cell current of both tandem configurations is nearly identical. This indicates that light transmission to the bottom cell is not affected by the absence or presence of a front-side texture in the wafer or whether the perovskite cell is separated from the $\mathrm{SHJ}$ cell by an optical coupling film or directly deposited on it.

The summed current of both subcells is $34.3 \mathrm{~mA} / \mathrm{cm}^{2}$ and $35.9 \mathrm{~mA} / \mathrm{cm}^{2}$ for the monolithic and mechanically stacked configuration, respectively, compared to $39.6 \mathrm{~mA} / \mathrm{cm}^{2}$ (without front-side metallization shadow losses) for the textured singlejunction SHJ cell, which is used for the 4-terminal tandem measurements. This difference can partially be explained by parasitic absorption losses in the $\mathrm{MoO}_{x}$ layer used in the tandem cell front electrode, which is induced by sputter damage during the IO:H layer deposition. Such losses could be reduced by using the more resilient and transparent $\mathrm{WO}_{x}{ }^{35}$

Reflection losses also contribute to the difference between tandem and SHJ single-junction EQE spectra (Figure S3). By replacing the rear-side textured wafer in the monolithic tandem with a double-sided textured one, while keeping everything else unchanged, we could expect to gain $\sim 2.6 \mathrm{~mA} / \mathrm{cm}^{2}$, resulting in a summed current of $36.9 \mathrm{~mA} / \mathrm{cm}^{2}$. Such a double-sided textured bottom cell would require the development of conformal perovskite cell deposition processes for highly textured substrates, which remains challenging. This calculation, however, already shows that the parasitic absorption losses discussed above are more important than reflection losses for the monolithic tandem with SST bottom cell and antireflective foil. Considering the integration of monolithic tandems into glass-glass encapsulated modules, where the application of such an antireflective foil is expected to be less effective, the use of a double-sided textured wafer would have a more pronounced effect on cell performance.

In summary, we demonstrated low-temperature NIR-transparent perovskite cells with up to $16.4 \%$ and $14.5 \%$ initial steady-state efficiencies for aperture areas of $0.25 \mathrm{~cm}^{2}$ and 1.015 $\mathrm{cm}^{2}$, respectively, obtained from maximum power point tracking for several minutes. We applied these solar cells in a mechanically stacked tandem configuration with a SHJ bottom cell and measured efficiencies of $23 \%$ and $25.2 \%$ with the 1.015 
$\mathrm{cm}^{2}$ and $0.25 \mathrm{~cm}^{2}$ top cells, respectively. On the basis of the same low-temperature cell fabrication process, we also developed a monolithic perovskite/SHJ tandem solar cell with a textured rear side. This led to an enhanced quantum efficiency in the near-infrared, resulting in an efficiency of $20.5 \%$ for an aperture area of $1.43 \mathrm{~cm}^{2}$. By comparing parasitic absorption and reflection losses in both tandem configurations, we identified performance-limiting factors as well as the potential for further efficiency improvement. The results presented here thus represent a further step toward the realization of large-area perovskite/silicon tandem solar cells with efficiencies beyond the single-junction limit.

\section{ASSOCIATED CONTENT}

\section{S Supporting Information}

The Supporting Information is available free of charge on the ACS Publications website at DOI: 10.1021/acsenergylett.6b00254.

Experimental methods; reflectance of DSP and SST tandem cells and a SHJ single-junction cell (PDF)

\section{AUTHOR INFORMATION}

\section{Corresponding Authors}

*E-mail: jeremie.werner@epfl.ch. Phone: +41 216954258.

*E-mail: bjoern.niesen@csem.ch. Phone: +41 327205606.

\section{Notes}

The authors declare no competing financial interest.

\section{ACKNOWLEDGMENTS}

We gratefully acknowledge Fabien Debrot for his support in the texturing and cleaning processes. The project comprising this work is evaluated by the Swiss National Science Foundation and funded by Nano-Tera.ch with Swiss Confederation financing; by the Swiss Federal Office of Energy, under Grant SI/501072-01; by the DOE under the FPaceII project (DEEE0006335); and by the Competence Center Energy and Mobility (CCEM) under the project CONNECT-PV. This work has received funding from the European Union's Horizon 2020 research and innovation programme under Grant Agreement No. 653296.

\section{REFERENCES}

(1) Green, M. A. Commercial progress and challenges for photovoltaics. Nat. Energy 2016, 1, 15015.

(2) Battaglia, C.; Cuevas, A.; De Wolf, S. High-efficiency Crystalline Silicon Solar Cells: Status and Perspectives. Energy Environ. Sci. 2016, 9, 1552-1576.

(3) Masuko, K.; Shigematsu, M.; Hashiguchi, T.; Fujishima, D.; Kai, M.; Yoshimura, N.; Yamaguchi, T.; Ichihashi, Y.; Mishima, T.; Matsubara, N.; et al. Achievement of More Than 25\% Conversion Efficiency with Crystalline Silicon Heterojunction Solar Cell. IEEE J. Photovoltaics 2014, 4, 1433-1435.

(4) Swanson, R. M. Approaching the $29 \%$ limit efficiency of silicon solar cells. Proc. 31st IEEE Photovoltaic Specialists Conference 2005, 889-894.

(5) Smith, D. D.; Cousins, P.; Westerberg, S.; De Jesus-Tabajonda, R.; Aniero, G.; Shen, Y. C. Toward the practical limits of silicon solar cells. IEEE J. Photovoltaics 2014, 4, 1465-1469.

(6) Holman, Z. C.; Descoeudres, A.; De Wolf, S.; Ballif, C. Record Infrared Internal Quantum Efficiency in Silicon Heterojunction Solar Cells With Dielectric/Metal Rear Reflectors. IEEE J. Photovoltaics 2013, 3, 1243-1249.

(7) Essig, S.; Steiner, M. A.; Allebé, C.; Geisz, J. F.; Paviet-salomon, B.; Ward, S.; Descoeudres, A.; Lasalvia, V.; Barraud, L.; et al.
Realization of GaInP/Si Dual-Junction Solar Cells with 29.8\% 1-Sun Efficiency. IEEE J. Photovoltaics 2016, 6, 1012-1019.

(8) Bett, A. W.; Philipps, S. P.; Essig, S. S.; Heckelmann, S.; Kellenbenz, R.; Klinger, V.; Niemeyer, M.; Lackner, D.; Dimroth, F. Overview about technology perspectives for high efficiency solar cells for space and terrestrial applications. In 28th European Photovoltaic Solar Energy Conference and Exhibition Proceedings, 2013.

(9) NREL Efficiency Chart. http://www.nrel.gov/ncpv/images/ efficiency_chart.jpg (accessed July 8, 2016).

(10) Saliba, M.; Matsui, T.; Seo, J.-Y.; Domanski, K.; Correa-Baena, J.-P.; Nazeeruddin, M. K.; Zakeeruddin, S. M.; Tress, W.; Abate, A.; et al. Cesium-containing Triple Cation Perovskite Solar Cells: Improved Stability, Reproducibility and High Efficiency. Energy Environ. Sci. 2016, 9, 1989-1997.

(11) De Wolf, S.; Holovsky, J.; Moon, S.-J.; Löper, P.; Niesen, B.; Ledinsky, M.; Haug, F.-J.; Yum, J.-H.; Ballif, C. Organometallic Halide Perovskites: Sharp Optical Absorption Edge and Its Relation to Photovoltaic Performance. J. Phys. Chem. Lett. 2014, 5, 1035-1039.

(12) Eperon, G. E.; Stranks, S. D.; Menelaou, C.; Johnston, M. B.; Herz, L. M.; Snaith, H. J. Formamidinium lead trihalide: a broadly tunable perovskite for efficient planar heterojunction solar cells. Energy Environ. Sci. 2014, 7, 982-988.

(13) Beal, R. E.; Slotcavage, D. J.; Leijtens, T.; Bowring, A. R.; Belisle, R. A.; Nguyen, W. H.; Burkhard, G.; Hoke, E. T.; McGehee, M. D. Cesium lead halide perovskites with improved stability for tandem solar cells. J. Phys. Chem. Lett. 2016, 7, 746-751.

(14) McMeekin, D. P.; Sadoughi, G.; Rehman, W.; Eperon, G. E.; Saliba, M.; Horantner, M. T.; Haghighirad, A.; Sakai, N.; Korte, L.; Rech, B.; et al. A mixed-cation lead mixed-halide perovskite absorber for tandem solar cells. Science 2016, 351, 151-155.

(15) Filipic, M.; Löper, P.; Niesen, B.; De Wolf, S.; Krc, J.; Ballif, C.; Topic, M. MALI perovskite/silicon tandem solar cells: characterization based optical simulations. Opt. Express 2015, 23, A263-A278.

(16) Lal, N. N.; White, T. P.; Catchpole, K. R. Optics and Light Trapping for Tandem Solar Cells on Silicon. IEEE J. Photovoltaics 2014, 4, 1380-1386.

(17) Almansouri, I.; Ho-Baillie, A.; Green, M. A. Ultimate efficiency limit of single-junction perovskite and dual-junction perovskite/silicon two- terminal devices. Jpn. J. Appl. Phys. 2015, 54, 08KD04.

(18) Uzu, H.; Ichikawa, M.; Hino, M.; Nakano, K.; Meguro, T.; Hernández, J. L.; Kim, S.; Park, N.; Yamamoto, K. High efficiency solar cells combining a perovskite and a silicon heterojunction solar cells via an optical splitting system. Appl. Phys. Lett. 2015, 106, 013506.

(19) Sheng, R.; Ho-Baillie, A. W. Y.; Huang, S.; Keevers, M.; Hao, X.; Jiang, L.; Cheng, Y.-B.; Green, M. Four-Terminal Tandem Solar Cells Using $\mathrm{CH} 3 \mathrm{NH} 3 \mathrm{PbBr} 3$ by Spectrum Splitting. J. Phys. Chem. Lett. 2015, 6, 3931-3934.

(20) Löper, P.; Niesen, B.; Moon, S.-J.; Martin de Nicolas, S.; Holovsky, J.; Remes, Z.; Ledinsky, M.; Haug, F.-J.; Yum, J.-H.; De Wolf, S.; Ballif, C. Organic-Inorganic Halide Perovskites: Perspectives for Silicon-Based Tandem Solar Cells. IEEE J. Photovoltaics 2014, 4, $1545-1551$.

(21) White, T. P.; Lal, N. N.; Catchpole, K. R. Tandem Solar Cells Based on High-Efficiency c-Si Bottom cells: top cell requirements for $>$ 30\% Efficiency. IEEE J. Photovoltaics 2014, 4, 208-214.

(22) Jiang, Y.; Almansouri, I.; Huang, S.; Young, T.; Li, Y.; Peng, Y.; Hou, Q.; Spiccia, L.; Bach, U.; Cheng, Y.-B.; et al. Optical Analysis of Perovskite/Silicon Tandem Solar Cells. J. Mater. Chem. C 2016, 4, 5679-5689.

(23) Albrecht, S.; Saliba, M.; Correa-Baena, J.-P.; Jäger, K.; Korte, L.; Hagfeldt, A.; Grätzel, M.; Rech, B. Towards optical optimization of planar monolithic perovskite/silicon-heterojunction tandem solar cells. J. Opt. 2016, 18, 064012.

(24) Bailie, C. D.; Christoforo, M. G.; Mailoa, J. P.; Bowring, A. R.; Unger, E. L.; Nguyen, W. H.; Burschka, J.; Pellet, N.; Lee, J. Z.; Grätzel, M.; et al. Semi-transparent perovskite solar cells for tandems with silicon and CIGS. Energy Environ. Sci. 2014, 8, 956-963.

(25) Fu, F.; Feurer, T.; Jäger, T.; Avancini, E.; Bissig, B.; Yoon, S.; Buecheler, S.; Tiwari, A. N. Low-temperature-processed efficient semi- 
transparent planar perovskite solar cells for bifacial and tandem applications. Nat. Commun. 2015, 6, 8932.

(26) Duong, T.; Lal, N.; Grant, D.; Jacobs, D.; Zheng, P.; Rahman, S.; Shen, H.; Stocks, M.; Blakers, A.; Weber, K.; et al. Semitransparent Perovskite Solar Cell With Sputtered Front and Rear Electrodes for a Four-Terminal Tandem. IEEE J. Photovoltaics 2016, 6, 679-687.

(27) Werner, J.; Dubuis, G.; Walter, A.; Löper, P.; Moon, S.-J.; Nicolay, S.; Morales-Masis, M.; De Wolf, S.; Niesen, B.; Ballif, C. Sputtered rear electrode with broadband transparency for perovskite solar cells. Sol. Energy Mater. Sol. Cells 2015, 141, 407-413.

(28) Chen, B.; Bai, Y.; Yu, Z.; Li, T.; Zheng, X.; Dong, Q.; Shen, L.; Boccard, M.; Gruverman, A.; Holman, Z.; Huang, J. Efficient Semitransparent Perovskite Solar Cells for 23.0\%-Efficiency Perovskite/Silicon Four-Terminal Tandem Cells. Adv. Energy Mater. 2016, 1601128.

(29) Mailoa, J. P.; Bailie, C. D.; Johlin, E. C.; Hoke, E. T.; Akey, A. J.; Nguyen, W. H.; McGehee, M. D.; Buonassisi, T. A 2-terminal perovskite/silicon multijunction solar cell enabled by a silicon tunnel junction. Appl. Phys. Lett. 2015, 106, 121105.

(30) Albrecht, S.; Saliba, M.; Correa Baena, J. P.; Lang, F.; Kegelmann, L.; Mews, M.; Steier, L.; Abate, A.; Rappich, J.; Korte, L.; et al. Monolithic Perovskite/Silicon-Heterojunction Tandem Solar Cells Processed at Low Temperature. Energy Environ. Sci. 2016, 9, 8188.

(31) Werner, J.; Weng, C.-H.; Walter, A.; Fesquet, L.; Seif, J. P.; De Wolf, S.; Niesen, B.; Ballif, C. Efficient Monolithic Perovskite/Silicon Tandem Solar Cell with Cell Area $>1 \mathrm{~cm}^{2}$. J. Phys. Chem. Lett. 2016, 7, 161-166.

(32) Li, X.; Bi, D.; Yi, C.; Decoppet, J.-D.; Luo, J.; Zakeeruddin, S. M.; Hagfeldt, A.; Gratzel, M. A vacuum flash-assisted solution process for high-efficiency large-area perovskite solar cells. Science 2016, 353, $58-62$.

(33) Wang, K.; Liu, C.; Du, P.; Zhang, H. L.; Gong, X. Efficient Perovskite Hybrid Solar Cells Through a Homogeneous High-Quality Organolead Iodide Layer. Small 2015, 11, 3369-3376.

(34) Schneider, B. W.; Lal, N. N.; Baker-Finch, S.; White, T. P. Pyramidal surface textures for light trapping and antireflection in perovskite-on-silicon tandem solar cells. Opt. Express 2014, 22, A1422.

(35) Werner, J.; Geissbuehler, J.; Dabirian, A.; Nicolay, S.; Morales Masis, M.; De Wolf, S.; Niesen, B.; Ballif, C. Parasitic absorption reduction in metal oxide-based transparent electrodes: application in perovskite solar cells. ACS Appl. Mater. Interfaces 2016, 8, 1726017267.

(36) Ulbrich, C.; Gerber, A.; Hermans, K.; Lambertz, A.; Rau, U. Analysis of short circuit current gains by an anti-reflective textured cover on silicon thin film solar cells. Prog. Photovoltaics 2013, 21, $1672-1681$.

(37) Escarré, J.; Söderström, K.; Despeisse, M.; Nicolay, S.; Battaglia, C.; Bugnon, G.; Ding, L.; Meillaud, F.; Haug, F. J.; Ballif, C. Geometric light trapping for high efficiency thin film silicon solar cells. Sol. Energy Mater. Sol. Cells 2012, 98, 185-190. 